\title{
CAMBIOS CELULARES CERVICOVAGINALES EN MUJERES CON VIH/SIDA
}

Martha Elisa Garcés Pinzón, Ivonne Jalith Soler Calvo*

\section{Resumen}

La población femenina que vive con VIH/SIDA está más predispuesta a sufrir alteraciones ginecológicas en las diferentes etapas de la infección debido a su inmunosupresión, tales como: infecciones oportunistas, facilidad en el desarrollo del HPV y lesiones intraepiteliales. Es así como surge la idea de analizar estos cambios citológicos, la frecuencia con que se presentan y comprobar lo que plantea la literatura acerca de este tema. Para ello, se trabajó con 50 mujeres infectadas por el VIH independientemente de la edad y del estado sintomático o no en que se encontraban, observándose en $20 \%$ de las muestras normales, cambios reactivos inflamatorios e infecciones, $16 \%$ de LSIL y $13 \%$ de HSIL y ASCUS.

\section{Introducción}

El virus de inmunodeficiencia humana (VIH) produce el síndrome de inmunodeficiencia adquirida (SIDA) y pertenece a un grupo conocido como retrovirus, es decir, que almacena su información genética en forma de ARN, a diferencia de la mayoría de los organismos vivientes que la almacenan como ADN. Este virus ataca una parte fundamental del sistema defensivo: los linfocitos T CD4 (+) y permanece latente durante mucho tiempo.

A medida que progresa el deterioro del sistema inmunológico, el individuo seropositivo comienza a desarrollar diversas infecciones oportunistas y tumores, que configuran el estado de SIDA.

Muchas de las infecciones oportunistas y el cáncer atacan el área cervicovaginal de la población femenina con VIH/SIDA, generándoles diversas atípias o cambios celulares que se evidencian en una citología cervicovaginal (CCV), siendo esta la prueba más eficaz para detectarlas y, posteriormente, tratarlas para mejorar la calidad de vida de la paciente y alterar el curso de la enfermedad. En esta sencilla razón radica el interés de nuestra investigación.

Desde el comienzo de la epidemia de SIDA se ha observado frecuentemente asociación entre las

VI semestre, Facultad de Citohistología, Fundación Universitaria de Ciencias de la Salud, Hospital de San José, Bogotá, D.C., Colombia. neoplasias de la vulva, cérvix y la región perineal en mujeres con VIH. Hay evidencia que el VIH facilita la infección por HPV, el cual es transmitido sexualmente y se relaciona con la causa de la LIE. Estas anormalidades deben ser estudiadas con CCV, colposcopias y biopsias dirigidas. A las mujeres con VIH se les debe practicar una citológica oncológica cervicovaginal cada seis meses y con más frecuencia cuando el CD4 sea menor de 200 células/mL.

\section{Materiales y métodos}

La investigación se llevó desde el primer semestre del año 2000 a noviembre de 2001, en las fundaciones e instituciones de asistencia integral para la población femenina viviendo con VIH/SIDA en Bogotá: Fundación Eudes, Fundación Caminos de Esperanza, Fundamor, Instituto de Seguros Sociales "ISS" (programa SIDA) y Hospital San José (infectología: programa SIDA)

Se trabajó con 50 mujeres infectadas por el VIH que accedieron al examen, independientemente de la fase (sintomática o asintomática) en que se encontraban. La muestra fue muy pequeña debido a que asisten muy pocas mujeres a los lugares ya mencionados en comparación con la población masculina, que es mayor. Sin embargo, es una muestra descentralizada y las conclusiones que se dan son sólo para este grupo de 50 mujeres. 
A las participantes primero se les hizo una charla de sensibilización acerca del examen; luego se les tomaron los datos clínicos básicos y unos adicionales como el recuento de linfocitos T CD4 (+) y la carga viral actual. Por último, se procedió a la toma citológica, obteniendo cuatro láminas para realizarles las coloraciones de Papanicolaou (PAP), hematoxilina eosina (HE), ácido periódico de Schiff(PAS) y Gram con el objeto de identificar y clarificar con más detalle los componentes y los agentes infecciosos (Figuras 1 a 4).

\section{Resultados}

De las muestras obtenidas se identificaron 11 normales $(20 \%), 11$ con cambios reactivos inflamatorios $(20 \%)$ y otras 11 muestras con infecciones
A
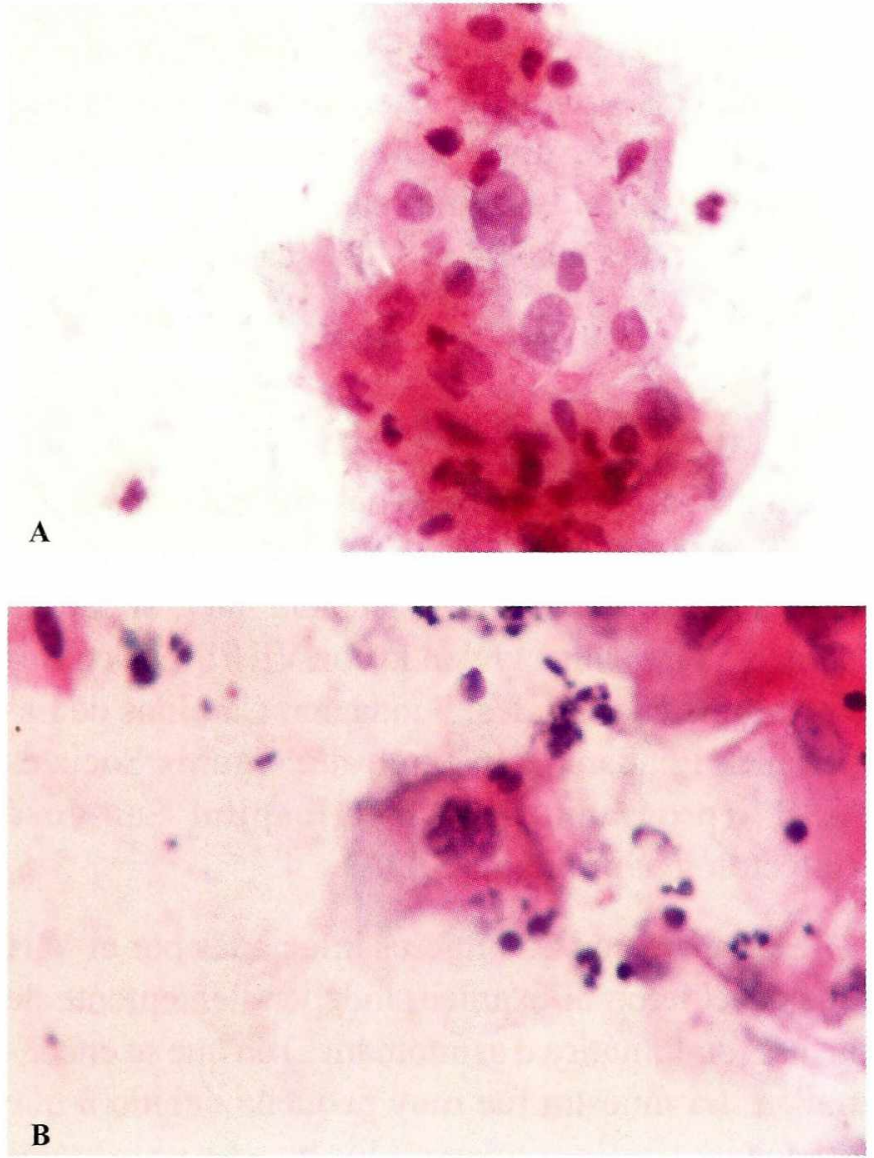

Figura 1. A) Imagen de PAP 40x de un ASCUS que sugiere un HPV. Nótese la hipercromasia moderada y anisonucleosis sin irregularidad nuclear significativa. B) Imagen de PAP 40x de infección por HPV que hace parte de las LSIL, en la cual se observa el "coilocito" con su halo perinuclear y núcleo irregular.
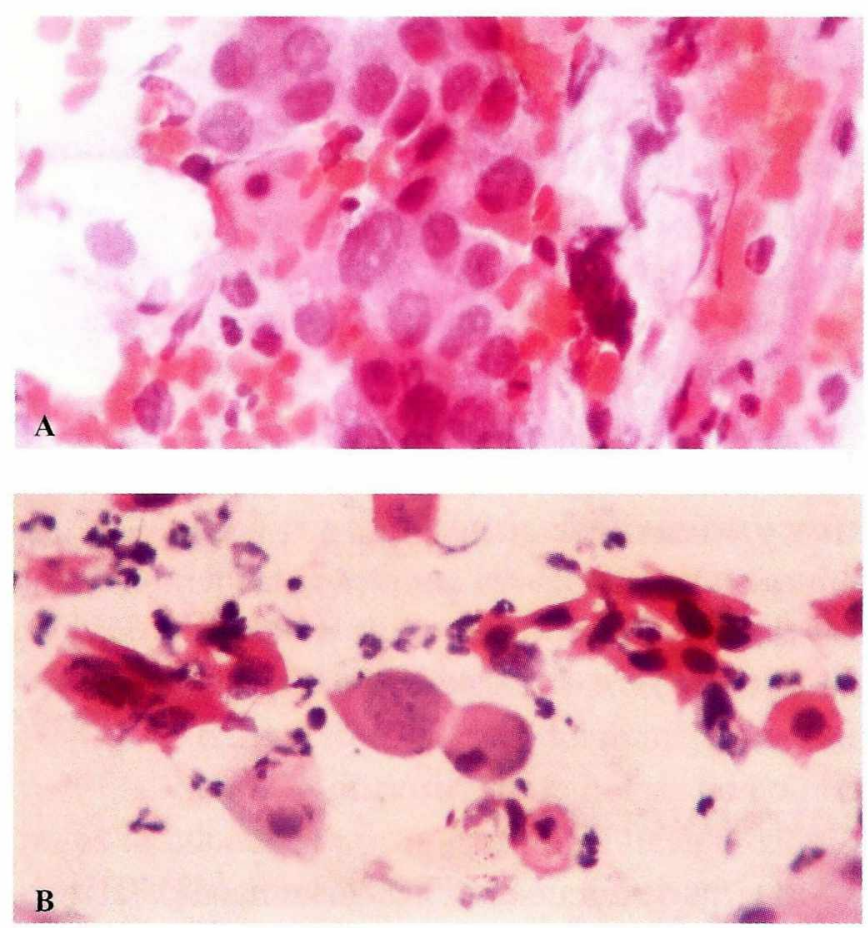

Figura 2. A) Imagen de PAP $40 x$ en donde se observa un HSIL (NIC II en metaplasia escamosa). B) Imagen de PAP 40x de un HSIL (carcinoma in situ ). En las imágenes, destaca la sobreposición y el pleomorfismo nuclear, la hipecromasia y la pérdida de la relación núcleo/citoplasma, a favor del núcleo.
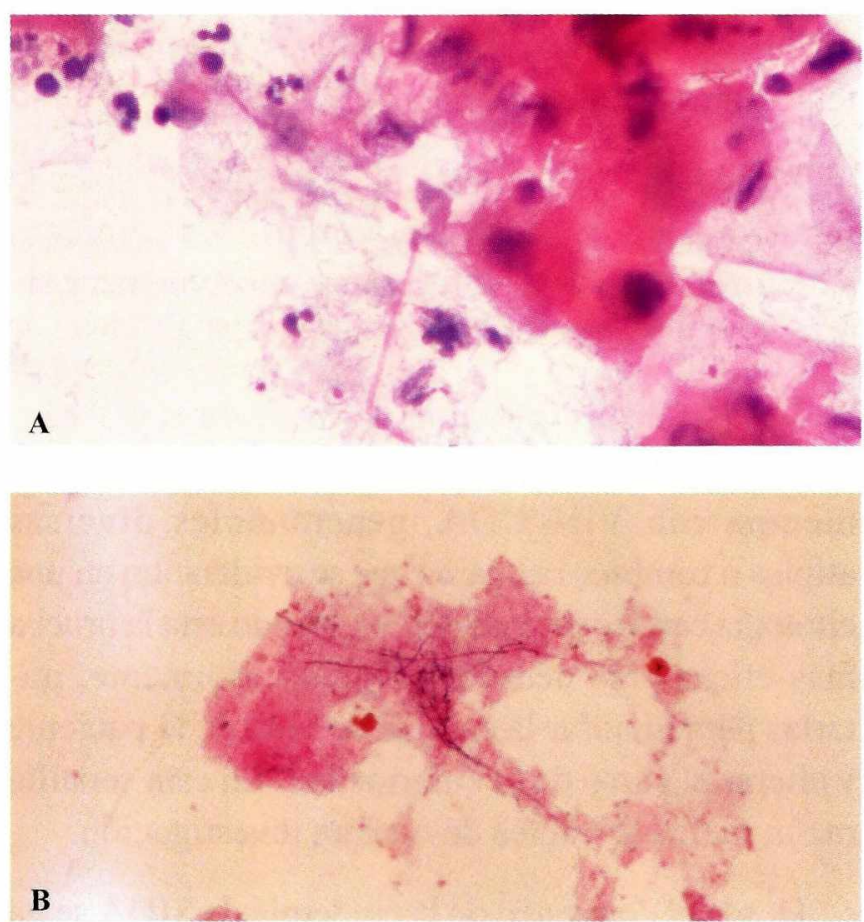

Figura 3. A) Imagen de PAP 40x de las hifas septadas y las atipias características que se producen en las células por los hongos, tales como: la eosinofilía y el agrandamiento nuclear. B) Imagen de PAS $40 x$ en donde se detallan con más claridad las hifas septadas. 

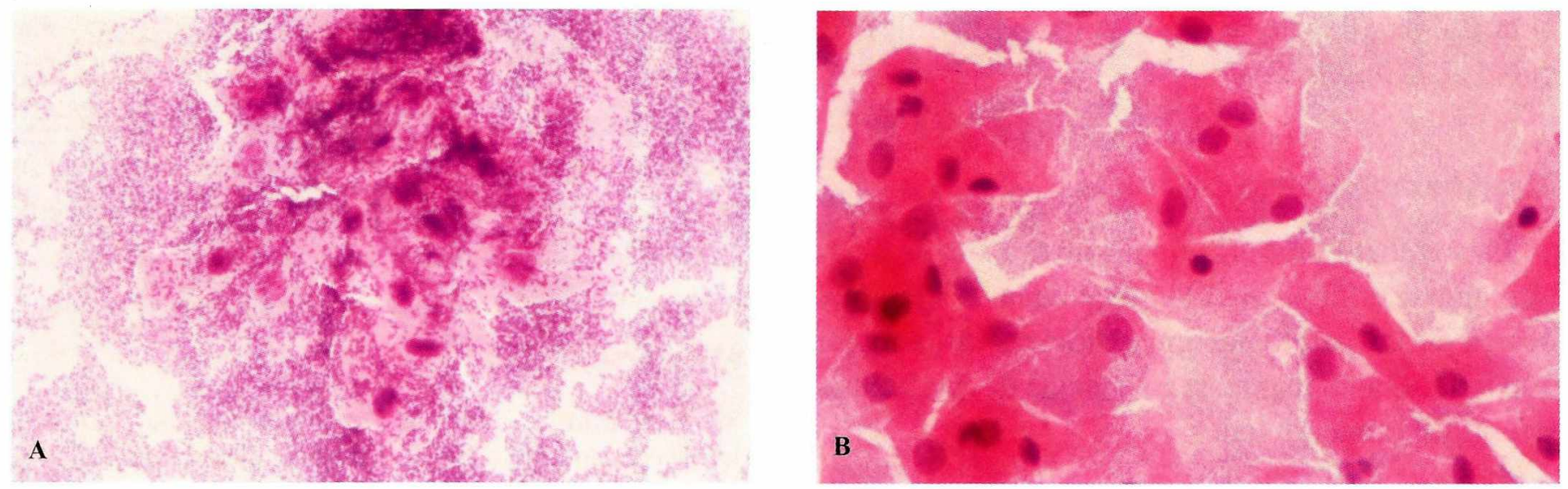

Figura 4. A) Imagen de PAP 40x de la infección por Gardnerella vaginalis. Nótese la nata grisácea sobre las células "células clave". B) Coloración de Gram 40x en donde se clarifican los cocos Gram positivos (+) de G. vaginalis recubriendo las células.

(20\%), de las cuales 4 (7\%) presentaban Gardnerella vaginalis y las restantes 7 (13\%) tenían hongos; además, 7 muestras (13\%) fueron clasificadas como atipias escamosas de significado indeterminado o ASCUS, discriminadas así: tres $(6 \%)$ con probable cambio reactivo, al igual que probable infección por el virus del papiloma humano (VPH) y una $(1,8 \%)$ probable lesión intraepitelial de bajo grado (LSIL). En total, 9 muestras (16\%) reportaron lesiones intraepiteliales de bajo grado: tres con VPH (5\%), cuatro (7\%) NIC I y dos (4\%) NIC I con VPH. De las siete (13\%) muestras con lesión intraepitelial de alto grado (HSIL) tres (6\%) fueron NIC II, en otras tres (65) se encontró carcinoma in situ y en una $(1,8 \%)$ NIC III (Tabla 1).

\section{Discusión}

El aumento de la frecuencia de las lesiones intraepiteliales y la candidiasis a pesar de la muestra tan pequeña, comprueba en este grupo lo planteado en la literatura acerca de la predisposición que tiene la población femenina con VIH/SIDA de desarrollar alteraciones ginecológicas. Ello expone la posibilidad de intensificar los programas de control citológico en estas mujeres para prevenir las LIE y

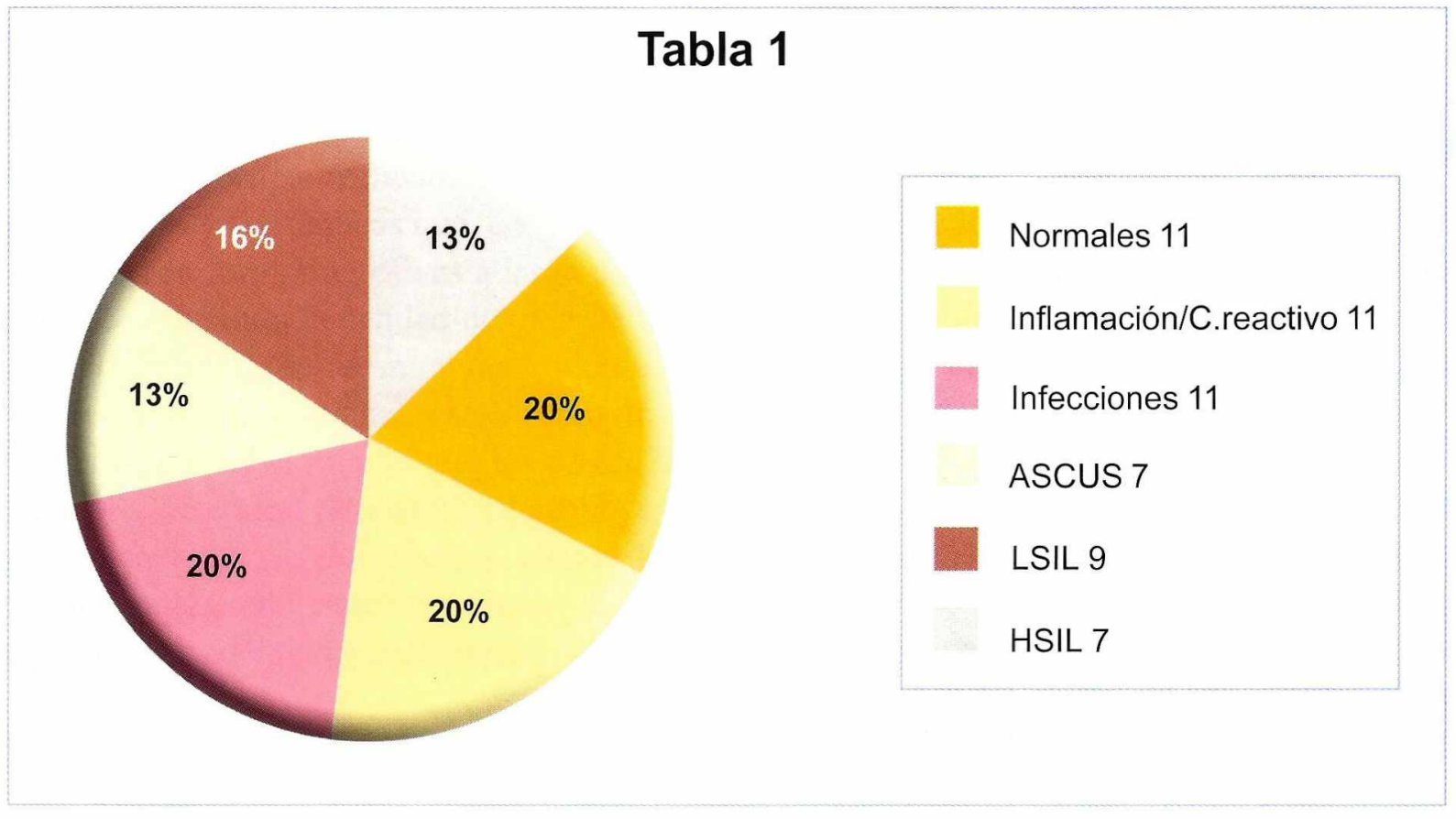


el carcinoma de cerviz y, por lo tanto, modificar el curso de la enfermedad.

\section{Conclusiones}

Esta trabajo permitió comprobar a través de la citología cervicovaginal lo que plantea la literatura acerca de las patologías ginecológicas de la mujer con VIH: el aumento en la frecuencia de candidiasis $\mathrm{y}$ lesiones intraepiteliales.

Además, tanto la neoplasia de células escamosas como la infección por VIH se transmiten por vía sexual y están relacionadas con el papilomavirus humano.

Está asociación no sólo depende del estado de inmunosupresión de la paciente sino de las prácticas sexuales de riesgo.
Por lo tanto, la intensificación de los programas de control no sólo reducirá el riesgo de transmisión de la infección por el virus de inmunodeficiencia humana y el papilomavirus humano, sino que serán útiles en la prevención del carcinoma de cuello uterino en la población femenina con VIH/SIDA.

\section{Bibliografía}

Kurmar, Cotran, Robbins. Patología humana. Editorial Interamericana Mc Graw Hill, quinta edición, México D.F.; 1995; 160-9.

Curtis H. Biología. Editorial Médica Panamericana $5^{\text {a }}$ ed. Buenos Aires, Argentina, 1993; 825-9.

Hellman S. Cáncer, principios y práctica de oncología. Editorial Médica Panamericana $5^{a}$ ed. 2000; 2460-2.

Vargas Téllez J. Afrodita y Esculapio, una visión integral de la medicina de la mujer. $3^{\mathrm{a}}$ ed.1992, cap V.

Muma RD, Lyons B. Manual del HIV para profesionales de la salud. Editorial Manual Moderno, 2000; cap VII. 